possessions, but as the old aristocracy knew, great possessions imply a sound sense of values and great personal responsibilities. Democracies still have this to learn. That is one of our greatest problems to-day.

But there is no need for pessimism. Looking back to the time of the first meeting of the British Association at Newcastle, one can find much ground for hope. Those, too, were days of terrible anxiety and strain, and yet there were then born many movements and activities which, scarcely noticed at first, blossomed later into full vigour, and greatly enriched our national life. How many important centenaries have been celebrated in the past few years. It may be that, unperceived by us, new movements are now starting into life, equally full of momentous possibilities for the future. Science can help us best if we have a sustaining faith, a high purpose in life and unflinching courage to pursue it.

\title{
SUMMARIES OF ADDRESSES OF PRESIDENTS OF SECTIONS
}

\section{SOME DEVELOPMENTS IN ASTRONOMICAL WISTRUMENTS}

GIR HAROLD SPEJCER JONES opens his $S$ presidential address to Section A (Mathematics and Physics) eighteenth cent $\mathrm{yy}$, astronomical observations were concerned flmost entirely with the determination of the esjitions and movements of the heavenly bodies. In toe seventeenth century the transit instrument became the standard instrument for the determination of right ascensions, while the mural circle was generally used for the measurement of declinations. Eventually the two instruments were combined to form the transit circle, which, with improvements in detail, has continued up to the present day to be used for the fundamental determination of positions. As requirements for precision have increased, its limitations have become more apparent. The errors of adjustment, continually changing with the am. bient temperature conditions, are difficult to control accurately; complicated flexure efiects, the error of figure of the pivots, and minute mechanical displace. ments in a telescope which is swung into different positions, introduce errors which are partly of a systematic nature and limit the accuracy with which a fundamental reference system of star places can be provided. Consideration is, therefore, being given to other designs of meridian instrument, likely to be less affected by systematic errors. In one of these the position of the instrument for each observation is determined by optical methods; in another the moving parts are reduced to a mirror, which can be turned to reflect light into one or other of two horizontal telescopes in the meridian, to the north and south of the mirror. For the determination of time, the development of the principle of Airy's reflex zenith tube to permit of photographic observa. tions provides a much higher accuracy than is attainable with the transit circle.

The developments in physical astronomy have caused meridian instruments to be superseded almost entirely by equatorial telescopes in most observatories except the principal national observatories. The refracting and reflecting types of telescope have alternated in favour. In the seventeenth century the large aberrations of the primitive simple lenses necessitated telescopes being made so long that they fell into disfavour. Newton devised the form of reflector which bears his name, but the first satis. factory reflecting telescope of this type was made by Hadley in 1720, who took the essential step of parabolizing the mirror. Dolland's patent of the achromatic objective in 1758 brought the refractor back into favour, but the size was limited by the poor quality of the optical glass. William Herschel's success in making larger mirrors of speculum metal, and the excellent quality of his telescopes made the reflector more popular. But the need for frequent repolishing of the speculum mirrors, the inconvenience of the altazimuth mounting, and the better refractors that became possible through Guinand's improvements in the making of optical glass and through his collaboration with Fraunhofer caused an almost complete reversion to the refractor. The equatorial mounting was developed by Sisson, Ramsden and Fraunhofer, among others. There was a rapid increase in aperture of the refracting telescope from Fraunhofer's $9 \frac{1}{2}$-in. Dorpat refractor of 1824 to Alvan. Clark's 40-in. Yerkes refractor of 1897. It had then reached the practicable limit in size, and it is unlikely that a larger aperture for a refractor will ever be attempted.

Liebig's discovery of a simple chemical process for depositing a film of silver on glass, together with Foucault's improvements in the methods of figuring and testing glass disks, caused attention to revert again to the refiector. The developments in technique due to Draper, Common and Ritchey made the modern large reflector possible. Its light grasp, its achromatism, and the ease with which it can bo used at different equivalent focal lengths make it a much more general-purpose instrument than the refractor, the main purpose of which is now in precise measurements. The use of an aluminium film, deposited by vacuum distillation, has enabled spectrographic observations with the reflector to be extended to the limit of atmospheric transparency.

'Pyrex' glass, because it has a lower coefficient of expansion and a higher thermal diffusivity than plate-glass, is now generally used for mirror disks. The thinner the disk the more rapidly it will reach a state of temperature equilibrium; but then also the more flexible it is, the more elaborate the support system must be. Sagging of the disk under its own weight can be counteracted by a properly. designed support system. Couder has derived criteria, based partly on dimensional considerations and partly on experimental results, from which the number of supports required for a disk of specified diameter and thickness can be estimated.

The principal defect of the paraboloidal reflector is the small angular field which is free from coma, seriously limiting its use for direct photography. It can be overcome by the use of a spherical primary mirror in conjunction with an aspherical plate in the plane of its centre of curvature, figured to correct for the spherical aberration of the primary. This: arrangement, generally called the Schmidt camera after its designer, has effective radial symmetry and 
gives a large field of sharp definition over a spherical focal surface the centre of which is at the centre of curvature of the primary. For investigations of stellar distribution, galactic structure, etc., it is unsurpassed. Used with an objective prism, it is ideal for the classification of the spectra of faint stars. There have been various modifications of the Schmidt design, such as the Schmidt-Cassegrain systems discussed by linfoot, with which a large flat field of good definition can be obtained. For the Isaac Newton reflector at the Royal Greenwich Observatory, it is proposed to make the primary mirror spherical with a radius of curvature of about $50 \mathrm{ft}$. and to use it in conjunction with a Schmidt correcting plate for direct photography. In spectrographic observations, this plate will be removed and one of two or more aspherical Gregorian secondaries, corrected to give good axial definition, will be used, according to the equivalent focal length required.

Different types of mounting have been used for large reflectors: the German mounting; the simple English mounting; the English yoke mounting; and the open fork mounting. The 200 -in. reflector at Mt. Palomar has a modified form of the yoke mounting, the upper bearing being in the form of an open horseshoe, enabling the telescope to be pointed to the pole. The fork mounting is in many ways the most convenient.

Many different instruments have been designed for special purposes in astronomy. Among these, one of the most important has been Lyot's coronograph, which has made it possible to study the sun's corona without a total eclipse of the sun. There have been important developments in details of design and construction, in methods of driving and guiding telescopes, in the design of spectrographs and other ancillary equipment. The design of almost every instrument presents special problems, and it is by the closest collaboration between the user, the designer, and the constructor that progress in observational astronomy can best be made.

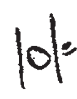

$\mathrm{A}$ $S$ the bactoryond on which to develop the subject of 6 s presidential address to Section B (Chemistry), Sir Alfred Egerton uses the records of the preforion in Newcastle. Whewellas president of the Section in 1838, WiAianson in 1863, Lothian Bell in 1889, and Hedderson in 1916. Sir Alfred directs special attention to the remarks of Sir William Armstrong, as president of the Association in 1863, on fuel economy, and to discussion in 1916 on the subject.

Omitting historical discussion of the influence of the early work on combustion on the birth of chemistry as a science, which has been a subject of earlier addresses to the British Association by Sir Edward Thorpe and others, Sir Alfred takes the work of Davy as having been the keystone of the particular field of combustion chemistry which still thrives. Davy, in his paper on combustion published by the Royal Society in 1817, described investigations on the limiting composition of combustible mixtures, observations on the structure and speed of flames, on the influence of inhibitors of combustion and on surface com. bustion, on the effect of pressure, the pressure developed on explosion which leads to measurement of flame temperatures, etc. Bunsen and his school developed Davy's work, and the knowledge gained had an influence on the establishment of the laws of thermodynamics and the development of physical chemistry. Combustion chemistry was further advanced by Berthelot's discovery of the detonation wave, and Mallard and le Chatelier's application of photography to the determination of the velocity of flames. These and other advances made by $\mathrm{H}$. $\mathrm{B}$. Dixon, W. A. Bone, A. Smithells and others, and by Haber, Nernst and others on the Continent, had their influence not only on chemistry, but also on technological progress during the period 1890-1920.

The study of combustion has had an even greater influence on the progress of chemistry since 1920 ; for in this latter period the study of gas reactions has led to a deeper understanding of the mechanism of chemical reactions, particularly in connexion with the combustion of phosphorus, of hydrogen and of hydrocarbons. Chain reactions provide an explanation for the limits of explosibility and for the behaviour of systems undergoing slow combustion, and the same notions have been applied to other problems which have had a great influence on recent advances, for example, the fission of atoms and production of new elements.

Sir Alfred refers to the conservation of fuel resources and their efficient utilization, pointing out the past wasteful methods of domestic heating. The possibilities in the development of gas turbines and distribution of energy in the form of gas produced by methods of total gasification are also mentioned. Looking back on the developments in the past fifty years, and bearing in mind the wonderful processes by which Nature synthesizes so many products, there is reason to believe that the achievements of chemistry will be no less great in the future.

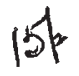

\section{RECENT WORK ON THE LOWER PALAOZOIC ROCKS}

T $\mathrm{N}$ his presidentifl address to Section C (Geology), I Prof. W. J. Puth points out that the history of the Lower Po(gedzol is the evolution of a geosyncline with its mand shelf-seas, which extended from south-wgst o north-east across the western part of Great Bftafn. This prolonged period of marine safimentation was accompanied by extrusive and nt ruove igneous activity and was closed by the Cadedohian mountain-building movements.

The Cambrian seas of the WeIsh-Midlands region and of Scotland with their contrasted faunas were probably separated from one another by a land-mass which occupied the Irish Sea and adjacent regions. This land-mass was doubtless the main source of supply of the sediments which were deposited to the south and north of it; to the south, the thick development of North Wales, and to the north there may have been an equally thick development of comparable lithology since part, at any, rate, of the Dalradian of the Southern Highlands is of Cambrian age. Geosynclinal conditions prevailed on each side of and adjacent to this Pre-Cambrian land-mass, while farther south and farther north, a smaller thickness of deposits accumulated in shelf-seas, although it is not known whether the Highland Border seas were continuous with those in the NorthWest Highlands. Movements of this Irish Sea geanticline controlled the characters of the sediments derived from it. 